\title{
Libras no ensino de inglês mediado pelas novas tecnologias: desafios e possibilidades
}

\author{
"Libras" (Brazilian Sign Language) in the \\ Technology-Mediated Teaching of English: \\ Challenges and Possibilities
}

Kátia Cristina do Amaral Tavares*

Universidade Federal do Rio de Janeiro

Rio de Janeiro - Rio de Janeiro / Brasil

Ana Paula Pires de Oliveira**

Universidade Federal do Rio de Janeiro

Rio de Janeiro - Rio de Janeiro / Brasil

RESUMO: Este estudo investiga a perspectiva de professores, intérpretes e alunos sobre o ensino de inglês mediado pelo uso das novas tecnologias e da Língua Brasileira de Sinais (Libras) em uma escola pública inclusiva, a fim de identificar os desafios enfrentados por eles nesse contexto e apontar possíveis formas de superá-los. Os dados foram gerados através de questionários, entrevistas, grupo focal, diário de pesquisa e gravação de aulas em vídeo. As aulas analisadas foram ministradas para uma turma de sétimo ano na sala de informática. Através da análise qualitativa dos dados, os desafios e as possibilidades observados foram agrupados em quatro núcleos de significado: (1) a mediação de três línguas: Libras, português e inglês; (2) a mediaçẫo do intérprete de Libras; (3) o professor e o uso de Libras; (4) a mediação da tecnologia.

PALAVRAS-CHAVE: Libras, ensino de inglês, tecnologia, inclusão, surdez.

ABSTRACT: This exploratory study investigates teachers', interpreters' and students' views about the teaching of English with the mediation of new technologies and of Brazilian Sign Language (Libras) in an inclusive public school in order to identify the challenges faced by the participants in such a context and point out possible ways of overcoming them. Data were generated through questionnaires, interviews, focus groups, research diaries, and video recordings of lessons. The analyzed lessons were taught to a seventh grade

\footnotetext{
*ktavares@uol.com.br

**anapaulamo2@yahoo.com.br
} 
class in the school's computer room. Through qualitative data analysis, the challenges and possibilities observed were grouped in four meaning categories: (1) the mediation of three languages: Libras, Portuguese, and English; (2) the mediation of the Libras interpreter; (3) the teacher and the use of Libras; (4) the mediation of technology.

KEYWORDS: Libras, English teaching, technology, inclusion, deafness.

\section{INTRODUÇÃO}

$\mathrm{Na}$ busca pelo direito à "igualdade de acesso", de acordo com os princípios de nossa própria Constituição, Lodi (2005) destaca a necessidade do aluno surdo de intensificar as relações dialógicas com seus pares e com os ouvintes, compreendendo a surdez como parte da pluralidade humana e considerando que os conflitos gerados pela diversidade cultural e linguística são fundamentais para seu desenvolvimento. Fonseca-Janes (2012), por sua vez, acredita que a escola inclusiva possa desempenhar um papel fundamental na formação de uma sociedade inclusiva.

É no contexto de uma escola pública inclusiva, cujas turmas são formadas por alunos surdos e ouvintes e onde os alunos surdos contam com um intérprete de Libras durante as aulas, que este trabalho foi desenvolvido. Neste estudo exploratório, de natureza etnográfica, analisamos aulas de inglês mediadas pelo uso das novas tecnologias e da Língua Brasileira de Sinais (Libras), ministradas para alunos do sétimo ano do Ensino Fundamental, e também investigamos a perspectiva dos participantes (professor, intérpretes e alunos) sobre as práticas pedagógicas adotadas, a fim de identificar os desafios enfrentados nesse contexto de inclusão e apontar possíveis formas de superálos. Destacamos que este trabalho é um estudo piloto vinculado ao recémcriado grupo de pesquisas da Universidade Federal do Rio de Janeiro sobre o uso de Libras em contextos mediados pela tecnologia (Libras-Tec/UFRJ).

A seguir, discutimos aspectos relacionados à aprendizagem de línguas (Libras, português e inglês) pelos surdos e o ensino de inglês para alunos surdos (e ouvintes), incluindo a questão da mediação da tecnologia. $\mathrm{Na}$ sequência, descrevemos o contexto de pesquisa, os participantes e os procedimentos de geração e análise de dados. Finalmente, apresentamos os resultados e tecemos algumas considerações. 


\section{APRENDIZAGEM DE LÍNGUAS POR SURDOS E O ENSINO DE INGLÊS}

Para o surdo, a linguagem gestual é uma forma natural de comunicação desde os primeiros anos; entretanto, como aponta Silva (2005), o processo de inclusão do surdo começa quando ele adquire a língua de sinais formal com seus pares. Com o aprendizado de Libras como primeira língua (L1), o português, que de início é uma língua estrangeira (LE) para o surdo, aos poucos, passa a ser a sua segunda língua (L2) - na modalidade escrita para a maioria, embora haja surdos oralizados. Mais tarde, a Libras é usada como embasamento linguístico no seu processo de aprendizagem de leitura/escrita de outras línguas, como o inglês, por exemplo.

Garcia (2003) destaca que as crianças ouvintes que entram na escola vêm falando uma língua nativa que aprenderam desde o nascimento em sua casa, enquanto as crianças surdas geralmente entram no jardim de infância com uma base de linguagem bastante limitada, por terem acesso à sua língua natural (ou seja, a língua de sinais) tardiamente. Esse fato leva essas crianças a um nível de comunicação mais primário, uma vez que o conhecimento avançado de língua de sinais é um preditor relevante à aprendizagem de outras línguas, como o português e o inglês.

Com relação à habilidade de escrita em língua estrangeira (LE), segundo Gesser (2009), o surdo enfrenta muita dificuldade, porque apresenta uma desvantagem ao lidar com a modalidade escrita das línguas em geral, que é a não familiaridade com o som produzido ao serem oralizadas, ou seja,

o fato de a escrita ter uma relação fônica com a língua oral pode de fato estabelecer outro desafio para o surdo: reconhecer uma realidade fônica que não lhe é familiar acusticamente. São como símbolos "abstratos" para o surdo (GESSER, 2009, p.56).

Apesar disso, com relação à possibilidade de se desenvolver a habilidade escrita sem a fala, Marcuschi acredita que seja possível devido ao fato de a fala "não representar a escrita e vice-versa", ou seja, há uma série de características da escrita, por exemplo, que não se podem reproduzir na fala, como tamanho e formato de letras (MARCUSCHI, 2010, p.17). Contudo, a escrita do aluno surdo, tanto na língua portuguesa (como L2) quanto na inglesa (como LE), tende a se apresentar em níveis de interlíngua - termo criado por Selinker (1972) para se referir ao sistema de transição que o aprendiz desenvolve durante o processo de aquisição/aprendizagem da segunda língua 
em que há uma interferência da língua materna em aspectos sintáticos, fonológicos, semânticos e lexicais, que são levados para a língua-alvo.

É importante o professor de alunos surdos (de qualquer disciplina e, em especial, os de língua) compreender todas essas dificuldades, quando avaliar o desempenho do aluno e, também, na hora de preparar suas aulas. Berto (2012) ressalta que, para compensar a falta da audição, os alunos surdos são muito visuais e, por isso, sugere o uso de recursos que privilegiem o uso de imagens, tais como fotos, vídeos, tirinhas, charges, softwares educacionais etc. Com isso, o aluno poderá associar a imagem da palavra escrita à imagem do objeto/palavra em questão.

A adoção de recursos visuais, entretanto, não é a única escolha metodológica a ser feita para garantir um ensino de inglês adequado às necessidades e possibilidades dos surdos. Segundo Miccoli (2005, p.31), "uma língua é usada para, entre muitas outras coisas, comunicar ideias e sentimentos, permitindo aos seus falantes participação social e cultural"; por isso, o aluno surdo não deve aprender apenas palavras soltas. Como qualquer outro aprendiz de uma LE, ele deve ser exposto a situaçóes de produção/consumo de enunciados que se situem no mundo, de acordo com necessidades e situações reais de interação.

Em sua pesquisa sobre os desafios do ensino da língua inglesa para surdos, entretanto, Carvalho (2013) observou que o ensino de inglês era pouco significativo para os alunos surdos investigados, pois estes não a utilizavam para a comunicação, enquanto alguns alunos ouvintes tinham certo contato com essa LE através de músicas, programas de TV, filmes e jogos de videogame. A exposição do aluno surdo a contextos reais de uso da língua inglesa se apresenta como um grande desafio para o professor de inglês.

Como a metodologia tradicionalmente utilizada na sala de aula de inglês é centrada no professor e privilegia a modalidade oral de comunicação (seja em inglês ou em português), a inclusão do aluno surdo costuma se estabelecer através de explicações dadas pela professora, geralmente em português e interpretadas em Libras por um intérprete que não sabe inglês. Assim, o contato do surdo com a língua inglesa durante as aulas costuma ser bastante reduzido.

Garantir o acesso do aluno surdo ao espaço regular não lhe garante o efetivo aprendizado. Peluso e Larrinaga (1996) apontam que, muitas vezes, os alunos inclusos passam a estar no mesmo espaço do ouvinte, mas não lhes são proporcionadas as mesmas possibilidades de aprendizagem, visto que muitas 
aulas continuam centradas na oralidade. Além disso, muitas vezes, é negado a esses alunos o acesso a recursos que poderiam facilitar seu aprendizado e autonomia, como o uso do computador.

Segundo Medeiros e Ferreira (2009), não há preparação do professor para receber esses alunos e, principalmente, há um déficit de documentos prescritos para orientar o professor no contexto de ensino de língua estrangeira para alunos surdos. Para elas, políticas de inclusão são impostas, mas o professor não encontra aporte para que elas sejam colocadas em prática ou o que encontra não é suficiente. Nos próprios Parâmetros Curriculares Nacionais, documento norteador para os professores, não é feita nenhuma consideração sobre a inclusão de surdos no ensino regular (MEDEIROS E FERREIRA, 2009).

Todavia, ao reconhecer que há limitações nas condições do ensino de idiomas nas escolas brasileiras que podem inviabilizar o ensino das quatro habilidades comunicativas, por exemplo, o documento orienta que o ensino da leitura deva ser enfatizado, já que esta é uma habilidade central na escola e é exigida em exames de acesso ao ensino superior. Tal ênfase na compreensão escrita se aplicaria ao ensino do surdo, embora não especificamente contemplado neste documento. Entretanto, se, por um lado, o foco na leitura para turmas inclusivas poderia ser justificado pela sua função social e também pelos objetivos realizáveis, tendo em vista as condiçôes existentes (BRASIL, 1998, p.21 e 24), por outro lado, excluir as habilidades de compreensão e produção oral das aulas de inglês implicaria reduzir o acesso dos alunos ouvintes à língua inglesa em uma modalidade que lhes é cada vez mais acessível através, por exemplo, de arquivos de vídeo e áudio disponibilizados gratuitamente na Internet.

Dessa forma, garantir ao aluno surdo o direito à aprendizagem da língua inglesa na modalidade escrita, sem retirar do aluno ouvinte o direito à aprendizagem das habilidades orais é um grande desafio, que demanda orientaçôes governamentais claras, um currículo e uma metodologia flexíveis, materiais didáticos que atendam à diversidade de necessidades dos alunos e professores com formação adequada para adotar e/ou adaptar tais materiais e métodos.

Em particular para o aluno surdo, a facilidade de acesso a imagens, animações e vídeos, proporcionada pela Internet, oferece novas formas de aprendizagem que não estavam tão disponíveis em um mundo analógico. Com as novas tecnologias, tornou-se muito mais acessível, por exemplo, 
registrar em vídeo alguém se expressando em Libras ou incluir uma janela com a interpretação em língua de sinais de vídeos feitos originalmente em outras línguas, facilitando, assim, a comunicação a distância feita em língua de sinais. Muitas vezes, entretanto, o professor rejeita as novas tecnologias por desconhecimento, medo, estranhamento, falta de formação ou por acreditar que não sabe fazer diferente do que faz, como destaca Bonilla (2011).

\section{CONTEXTO DE PESQUISA E PARTICIPANTES}

O presente estudo foi conduzido em uma escola pública de Duque de Caxias, município da região metropolitana do Rio de Janeiro, onde uma das autoras atua como mediadora de tecnologia. Na proposta educacional adotada pela rede de ensino desse município, parte-se do princípio do aprendizado da língua de sinais como primeira língua, no período em que a criança tem de zero a seis anos e, a partir dessa base linguística, inicia-se o aprendizado do português escrito com metodologias de ensino de segunda língua.

A rede municipal orienta que a criança surda seja encaminhada para uma turma formada apenas por surdos (Classe Especial), acompanhada por um professor especializado, e que nela permaneça até completar o quinto ano do Ensino Fundamental. Caso seja opção dos pais, o português oral pode ser ensinado em período contrário à escolarização, sob a responsabilidade de fonoaudiólogos e fora da unidade escolar. Somente depois dessa fase, o aluno é encaminhado ao sexto ano do ensino regular juntamente com alunos ouvintes. Durante as aulas, o aluno é acompanhado por um intérprete e, no contraturno, também conta com um professor em Sala de Recursos, onde deve ser feita uma atividade especializada de reforço para complementar o aprendizado com a língua de sinais, uma vez que os professores regentes do sexto ao nono ano, diferentemente do professor da Classe Especial, não dominam a língua de sinais.

Ao iniciar o sexto ano, portanto, os alunos das turmas inclusivas se deparam com algumas modificações estruturais em seu ambiente escolar, passando a ter oito professores de disciplinas diferentes, a presença do intérprete de Libras, alunos surdos e ouvintes numa mesma sala e a aprendizagem de um novo idioma (no caso, o inglês). Além disso, na escola em questão, os alunos também participam de um Projeto de Aprendizagem com o uso de novas tecnologias. Dessa forma, a escola objetiva promover a inclusão dos alunos surdos em três esferas: social, com a inserção dos 
alunos em turmas regulares; digital, com atividades mediadas pelas novas tecnologias; e linguística, pois, através da Libras como língua materna, buscase o letramento do aluno na língua portuguesa (como segunda língua) e em uma língua estrangeira (no caso, o inglês).

Os alunos selecionados como sujeitos desta pesquisa já passaram pelo período de adaptação à nova configuração de ensino iniciada no sexto ano e estão agora em uma turma inclusiva do sétimo ano do Ensino Fundamental. A faixa etária dos alunos é diferenciada, pois o aluno ouvinte geralmente conclui o quinto ano por volta dos 10 anos e o aluno surdo, por volta dos 15 anos.

Segundo dados de um questionário destinado a traçar o perfil dos alunos surdos da escola investigada, antes de ingressarem no sexto ano, a maioria deles já havia estudado nessa mesma escola em Classe Especial. Somente um aluno havia estudado em escola só de ouvintes e outro, em escola só de surdos (INES), mas depois optaram pela escola inclusiva. Os dados também indicaram que a maioria dos alunos não nasceu surda, tendo a surdez se iniciado por alguma doença na infância. Além disso, não há outros surdos na família e nem alguém em casa que saiba Libras. Assim, a escola é vista como o único local onde podem usar e aprender a língua de sinais.

A carga horária de inglês é de dois tempos semanais de 50 minutos, ministrados uma vez por semana em uma sala de aula tradicional e/ou na sala de aula de informática. A iniciativa de realizar aulas de inglês na sala de informática surgiu a partir de uma parceria entre a professora de inglês da turma e a mediadora de tecnologia da escola, que é professora de inglês por formação e uma das autoras deste trabalho. Ambas decidiram conduzir um projeto-piloto a fim de proporcionar aos alunos a oportunidade de aprender e empregar a língua estrangeira com o uso das novas tecnologias.

A sala de informática conta com um data show e dez computadores equipados com Linux Educacional (LINEDUC), dicionário de Libras e Internet. Os computadores são posicionados junto às paredes e, diante de cada um, há duas ou três cadeiras para os alunos.

Como a sala de informática é pequena, a turma precisou ser dividida em dois grupos pela professora de inglês. Enquanto um grupo estava na sala de aula tradicional com a professora de inglês, o outro grupo ia para a sala de informática para ter aula com a mediadora de tecnologia, que atuava como professora de inglês nesse contexto. No segundo tempo de aula, os grupos trocavam de ambiente e de atividade. Em raras ocasiōes, a professora regente 
e a mediadora de tecnologia puderam ficar juntas, ou com toda a turma reunida na sala de informática.

Como exemplos de atividades nas aulas de inglês na sala de informática, vamos descrever, resumidamente, aquelas desenvolvidas nas aulas cujos trechos são discutidos neste artigo. Em duas dessas aulas, houve atividades de revisão de números e cores a pedido da professora de inglês. Para rever os números, os alunos utilizaram um jogo on-line em que tinham de fazer cálculos e responder em inglês. Para rever as cores, assistiram a um vídeo de apresentação das cores em inglês, incluindo sua grafia e também usaram um jogo on-line. Em uma tentativa de oferecer um contexto para a revisão desses conteúdos, os alunos visitaram os sites de compras de roupas <www.gap.com $>$ e $<$ handsay.com $>$ (que comercializa camisetas com mensagens em inglês para surdos), onde podiam observar, por exemplo, os nomes em inglês das cores dos produtos e os preços.

$\mathrm{Na}$ segunda aula, os alunos completaram um pequeno texto, em inglês, sobre si mesmos, com informaçôes como nome, idade, cor favorita e outras que já haviam aprendido em inglês e ilustraram esse texto. Os alunos digitaram e apresentaram seus textos, lendo-os em voz alta (no caso dos ouvintes) ou com sinais em Libras (no caso dos surdos).

Em outras aulas, as atividades focalizaram vocabulário em inglês relacionado ao mundo da tecnologia. Os alunos pesquisaram na Internet o significado de palavras como link, hiperlink, Internet, print, Facebook, tag, entre outros, com a utilização do Google Tradutor, do dicionário de Libras instalado e com a ajuda do intérprete, e produziram slides ilustrados para apresentação para a turma e a professora de inglês.

\section{PROCEDIMENTOS DE GERAÇÃO E DE ANÁLISE DOS DADOS}

Neste estudo exploratório, de natureza etnográfica, os dados foram gerados através dos seguintes instrumentos: gravação em vídeo das aulas de inglês, ministradas na sala de informática, para a turma selecionada para este estudo; questionário e entrevista com a professora de inglês; questionário para os alunos ouvintes da turma em foco; entrevistas com alunos surdos da turma em foco (com auxílio de um intérprete de Libras), gravadas em vídeo; grupo focal com os intérpretes de Libras da escola (incluindo o intérprete das aulas gravadas); e diário de pesquisa da professora (mediadora de tecnologia).

A partir da análise qualitativa dos depoimentos dos participantes, foram identificados desafios e possibilidades observados por eles no seu 
contexto de ensino-aprendizagem de inglês, com a mediação de Libras e de novas tecnologias. Tais desafios e possibilidades foram, então, agrupados em quatro núcleos de significado: (1) a mediação de três línguas: Libras, português e inglês; (2) a mediação do intérprete de Libras; (3) o professor e o uso de Libras; (4) a mediação da tecnologia. $\mathrm{Na}$ fase posterior de análise, foram identificados trechos de aulas que se relacionavam com os depoimentos dos participantes e poderiam enriquecer a discussão dos dados.

\section{RESULTADOS}

Nas subseçōes a seguir, apresentamos e discutimos os dados relativos a cada um dos quatro núcleos de significado já mencionados. Os nomes dos participantes são fictícios.

\subsection{A mediação de três línguas: Libras, português e inglês}

O uso das três línguas - Libras, português e inglês - que ocorre nas aulas de inglês é visto pelos alunos da turma em foco como uma oportunidade de aprendizagem e interação, como pode-se observar no relato abaixo.

"Os surdos, além de aprender a língua portuguesa, aprendem inglês e nós aprendemos a libras e o inglês." (Carol, aluna ouvinte)

Os depoimentos a seguir também sugerem que, apesar de algumas dificuldades durante as aulas, há um esforço para viabilizar a interação entre alunos surdos e ouvintes, seja com uso de leitura labial, mensagens por escrito, gestos ou interpretação em Libras.

"Eu gosto de ficar na sala de aula com os ouvintes, porque nós compartilhamos... Eles aprendem sinais, é muito legal. Às vezes, eu não entendo, porque eu não tenho boa oralização, aí eles param e conseguem explicar." (Janete, aluna surda)

"Eu me comunico [com os surdos] falando devagar, porque alguns conseguem fazer leitura labial, com gestos e com o intérprete." (Nelson, aluno ouvinte)

Essa disposição para superar as dificuldades de comunicação entre surdos e ouvintes, entretanto, não é unânime. Lucas, aluno ouvinte, por exemplo, prefere evitar a interação com os surdos. 
"Eu prefiro ficar com ouvintes porque com surdos a comunicação é difícil." (Lucas, aluno ouvinte)

Hélio, por sua vez, se esforça para se comunicar com os surdos, mas reconhece que, durante as aulas, muitos alunos ouvintes se sentem incomodados com a dificuldade dos surdos com a língua portuguesa (que é língua materna para os ouvintes, mas segunda língua para os surdos).

"Eu me comunico com eles às vezes com Libras (com o pouco que eu sei rsrs) e, às vezes, com gestos, mas muitos de nós não gostamos, porque às vezes eles atrapalham muitas aulas, por causa da dificuldade com o Português." (Hélio, aluno ouvinte)

As dificuldades dos surdos, porém, não se restringem à língua portuguesa. Como observado pela intérprete Carla, alguns alunos surdos não têm fluência em sua própria língua materna, Libras.

"Muitos alunos chegam sem Libras, que é a primeira língua deles. Não é que seja sem, mas não têm a fluência, né? Então tem essa dificuldade de ensino... Quem não tem a Libras, não tem aquele acompanhamento.” (Carla, intérprete)

A professora de inglês também observa essas dificuldades dos alunos surdos com Libras e português. No depoimento abaixo, ela sugere que a aprendizagem de inglês, uma terceira língua, pode ser ainda mais difícil, considerando que os alunos ainda não são proficientes nas duas primeiras línguas.

"O surdo parece que entra em desvantagem no nosso contexto escolar. Isso não apenas porque Libras é a "primeira" língua, português a segunda e, enfim, inglês seria uma terceira. O fato é que eles parecem não dominar Libras quando entram na escola. Então, ainda estão em processo, tanto com Libras, como com português e aí, ainda vem o inglês. A criança ouvinte, ainda que os pais não sejam leitores, talvez elas sejam expostas a livros, ouçam na escola, veem na TV ou mesmo leiam os livros por si mesmas. Posso estar equivocada, mas acho que não é o que acontece com os surdos. Em casa, muitos familiares não sabem Libras. A escola tem que dar conta de introduzir o aluno a essa língua. Daí, muitos quando ainda estão em processo de alfabetização, com repertório linguístico reduzido ainda, já devem estar na sala com os ouvintes." (Eliane, professora de inglês) 
No depoimento a seguir, Aldo, intérprete da turma em foco neste trabalho, também destaca o desafio que representa a aprendizagem de uma terceira língua (no caso, o inglês) para os surdos, ainda que, por vezes, as aulas focalizem apenas itens de vocabulário. Para ele, é necessário que o aluno surdo esteja muito interessado nas atividades e conteúdos propostos para superar suas dificuldades de aprendizagem de uma língua estrangeira. Aldo ainda aponta que a mediação de três línguas (inglês, português e Libras) durante as aulas de inglês também torna o trabalho do intérprete mais árduo.

“(...) pro surdo [o inglês] já se torna uma terceira língua, onde a escrita é diferenciada e, pra eles, que já entram numa língua, no caso, a língua de sinais, você tem que tentar ouvir em inglês, pensar em português e traduzir pra Libras. Então, fica pesado não só pro intérprete, mas também pro surdo. E pra eles, na verdade, só algumas palavras, algo bem suave tipo cores, números, porque o próprio surdo ele tem a vontade de aprender, mas pra eles é difícil. E a dificuldade acaba criando um bloqueio pra eles. Só se tiver algo que interesse muito mesmo assim pra eles." (Aldo, intérprete)

A dificuldade de interpretação das aulas de inglês para Libras também é destacada por Aldo no trecho abaixo. Como o intérprete não sabe inglês, a professora precisa traduzir sua fala para o português para que, então, ele possa interpretar de português para Libras. Entretanto, se a professora traduz para o português o que fala em inglês, o aluno ouvinte não se esforça para compreender o que é dito em inglês. Dessa forma, cria-se um impasse.

"Só consigo interpretar bem aquilo que vejo com clareza e eu não sei quase nada de inglês. Quando a professora fala inglês na sala, ela me quebra e aí, se ela traduz, o ouvinte não se esforça pra entender." (Aldo, intérprete)

Em seu diário de pesquisa, a professora Ana relata que, embora tivesse planejado evitar traduzir do inglês para o português ao longo da aula, notou ter utilizado esse procedimento com frequência para viabilizar a interpretaçáo do que ela dizia para Libras, já que o intérprete não era proficiente em inglês.

“(...) frequentemente traduzia do inglês para português, embora tivesse planejado, inicialmente, não fazer isso, talvez para contemplar o intérprete que nem sempre poderia traduzir o que eu falava em inglês." (Ana, professora, mediadora de tecnologia) 
Outra dificuldade enfrentada nas aulas de inglês e mencionada pelo intérprete Aldo está relacionada às atividades orais. A esse respeito, ele apresenta duas visões contraditórias em dois depoimentos distintos. Em um primeiro depoimento, reproduzido abaixo, ele afirma que os surdos não se sentem excluídos por não realizarem atividades de pronúncia (que, teoricamente, poderiam ser realizadas pelos surdos que oralizam), tendo em vista que, segundo ele, "não gostam de falar inglês".

"Quando ela [professora de inglês] faz atividade de pronúncia é só com os ouvintes, os surdos fazem outra atividade, mas não se sentem excluídos, pois não gostam de falar inglês.” (Aldo, intérprete)

A opinião de Aldo parece ser confirmada pela preferência de Ângela e de Tânia, alunas surdas que oralizam, por usar a língua de sinais em vez do inglês, como se pode ver no trecho de aula transcrito a seguir.

(A professora propõe para a turma que os surdos leiam seus textos em Libras e ela repita em inglês e os ouvintes falem em inglês e ela passe para Libras. Os alunos concordam.)

PROFESSORA: Angela (aluna surda que oraliza), vai falar em libras ou vai falar em inglês?

ALUNA SURDA: Libras.

(...)

PROFESSORA: Agora você (dirigindo-se a outra aluna surda que oraliza), quer falar inglês ou libras?

ALUNA SURDA: Quero falar.

PROFESSORA: Mas tem que ser inglês.

ALUNA SURDA: Sei falar inglês, não. (risos)

PROFESSORA: Eu ajudo, você repete: My name is ...

ALUNA SURDA: Tânia

PROFESSORA: Tem que repetir tudo, vai... (Aluna não responde.) Acho que ela não tá ouvindo (dirigindo-se ao intérprete).

ALUNA SURDA: Eu num tô ouvindo não, tô com a bateria fraca.

PROFESSORA: Então você pode ir lendo lá e ir tentando fazer em Libras (ela faz os sinais em Libras e digitaliza em inglês os números e cores).

Em um segundo depoimento, entretanto, o intérprete Aldo sugere que os surdos podem se sentir excluídos por não poderem acompanhar os alunos 
ouvintes nesse tipo de atividade. Para ele, atividades com palavras escritas são as ideais para os surdos.

"Quando o professor passa no quadro as cores com a tradução do lado, ótimo, o aluno vai copiar e saber que o "yellow" é o amarelo. Agora, muitas das vezes quando o professor pronuncia ou fala "vamos pronunciar", eu acho que fica chato pro aluno surdo. Não tem como acompanhar a turma e ele acaba sendo excluído ao invés de ser incluído em muito boa parte da aula de inglês." (Aldo, intérprete)

A intérprete Joana concorda e destaca que, nas atividades orais das aulas de inglês, o aluno surdo acaba respondendo ao professor sempre em Libras e não em inglês, que é a língua a ser aprendida nessas aulas. Para Joana, quando o aluno não usa a língua inglesa nas aulas, é um desperdício de tempo.

"Quando fica naquela situação de repetir, o aluno repete, o aluno repete... por mais que eu tente passar isso pro surdo, ele só vai estar respondendo em língua de sinais brasileira. Ele não está acompanhando a aula de inglês da mesma forma que o ouvinte. E essa aula, pra mim, ela é perdida, porque treinar em Libras, ele já sabe. Então, se você não passa numa forma americana, pra ficar passando numa forma brasileira, essa aula é perdida, não pegam nada." (Joana, intérprete)

Como se pode observar em um trecho de aula transcrito a seguir, para que os alunos surdos possam participar da atividade, na qual os ouvintes dizem (e não escrevem) palavras em inglês, a professora pede aos alunos surdos que façam o sinal de cada letra da palavra em inglês. Em outras palavras, pode-se dizer que os surdos "soletram" em Libras a palavra em inglês (em vez de escrevê-la ou de dizê-la, o que, teoricamente, seria possível para os surdos que oralizam). Como é difícil para o intérprete observar a digitalização de todos os surdos ao mesmo tempo, ele pede à professora que selecione um aluno por vez. Em seguida, para incluir todos os alunos, a professora também convida alunos ouvintes a dizer os nomes das cores em inglês.

PROFESSORA: Olha, eu quero os ouvintes falando e os surdos digitalizando em inglês (aponta para a palavra "color" no quadro e mostra um objeto vermelho). ALUNOS: R-E-D (os surdos digitalizam a palavra em inglês utilizando o alfabeto, mas sem utilizar o sinal da cor em Libras e os ouvintes pronunciam "red"). 
INTÉRPRETE: Escolhe uma pessoa só pra ela responder.

PROFESSORA: Teresa.

ALUNA SURDA: (digitaliza) R-E-D.

PROFESSORA: Agora um ouvinte (mostrando um objeto preto).

ALUNA OUVINTE: Preta, black.

PROFESSORA: Ok (mostra um objeto azul). Olha lá, ela sabe.

ALUNO SURDO: (digitaliza) B-L-U-E. (A professora mostra um objeto rosa.) ALUNA SURDA: (digitaliza) $P-I-N-K$.

$\mathrm{Na}$ sequência, uma aluna surda digitaliza errado e imediatamente se corrige. Nesse momento, a professora percebe que a mesma cor digitalizada (ou seja, "soletrada" em Libras) por um surdo também pode ser dita em voz alta por um aluno ouvinte, já que são duas tarefas diferentes. Ela, então, pede que um aluno ouvinte diga em inglês o mesmo nome da cor mostrada pelo professor e "soletrada" pela aluna surda.

ALUNA SURDA: $G-R-E-N-N$, G-R-E-E-N (surdo levanta o dedo e digitaliza errado e conserta)

PROFESSORA: E os ouvintes? Agora eu quero um ouvinte, como é que fala essa cor em inglês?

ALUNO OUVINTE: Green.

Ainda na sequência dessa atividade, a professora corrige a digitalização de "yellow". Nesse caso, a aluna parece não saber a grafia correta da palavra e tem a oportunidade de aprender. Note-se, portanto, que, para os alunos surdos, não se trata de uma atividade oral, mas sim de ortografia.

(A professora mostra um objeto amarelo.)

ALUNA SURDA: (digitaliza) Y-E-L-L-O-U.

PROFESSORA: Não, éw (a professora sinaliza e a aluna corrige digitalizando novamente).

\subsection{A mediação do intérprete de Libras}

$\mathrm{Na}$ inclusão do surdo no ensino regular, o novo personagem na configuração da sala de aula é o intérprete de língua de sinais, que busca facilitar a comunicação entre surdos e ouvintes. A presença do intérprete é garantida por lei para o aluno surdo, mas seu papel ainda gera dúvidas para 
muitos envolvidos, inclusive para o próprio intérprete, que frequentemente atua ou é convidado a atuar como professor. O decreto n. ${ }^{\circ}$ 5.626, de 22 de dezembro de 2005, regulamenta sua formação, mas, segundo Medeiros e Ferreira (2009), muitos dos profissionais que hoje atuam nessa área não passaram por nenhum curso de graduação específico que os preparasse para interpretar as aulas, especialmente as de inglês.

Dito de modo bastante simplificado, a função do intérprete é traduzir para Libras o que se fala em sala de aula e, para o português, o que for dito em Libras. Como, entretanto, a interação em sala de aula costuma ser bastante dinâmica, com conversas paralelas sobre temas mais ou menos relacionados ao conteúdo da aula em si, e pessoas se dirigindo a um ou mais indivíduos posicionados em pontos diferentes da sala, o trabalho do intérprete envolve vários desafios, incluindo a escolha sobre o quê exatamente deve ser interpretado.

Para a professora de inglês da turma observada neste trabalho, o papel do intérprete é facilitar a comunicação entre professor e alunos, mas ela observa que, na sua sala de aula, o intérprete, provavelmente por ser o único participante adulto que sabe Libras, acaba indo além de sua função primária, como podemos ver no depoimento a seguir.

“...a função de um intérprete é servir de ponte de comunicação entre professor-alunos-professor. Mas vejo que o intérprete ajuda de outras formas: verifica se eles [alunos surdos] entenderam, se estão copiando certo, ensina - na medida do possível. Ele se torna um anjo da guarda. Afinal, mesmo que eu tenha boa vontade, só com sorriso não consigo me comunicar com eles." (Eliane, professora de inglês)

A mediação do intérprete também é valorizada pelos alunos, como se pode ver nos trechos a seguir, em que tanto um aluno surdo quanto um aluno ouvinte declaram aprender com o intérprete.

"O intérprete é muito importante porque ensina, ajuda a gente a aprender a escrita, ele tem a importância de ouvir e passar pra Libras." (Ícaro, aluno surdo)

"Eu acho que é legal porque com os intérpretes eu aprendo também, tem dois professores." (Leo, aluno ouvinte) 
Com relação às falas e aos conteúdos que devem ser efetivamente interpretados, Aldo, intérprete da turma cujas aulas foram gravadas, destaca, no trecho a seguir, a importância de passar para Libras não apenas o que é dito pelo professor, mas também outras falas afins aos conteúdos da aula, para que o surdo não se restrinja a uma aula expositiva, centrada no professor, mas possa participar mais plenamente da interação em sala de aula:

“...às vezes nem é só o que o professor falou, mas se a aula girou em torno daquilo ali, eu tenho que interpretar, se não, o surdo fica boiando." (Aldo, intérprete)

A preocupação do intérprete em integrar os surdos às diversas situações de interação ocorridas em sala de aula nos remete à visão, apontada por Miccoli (2005), de que uma língua oferece aos seus usuários participação social e cultural.

No depoimento a seguir, a mesma postura é reforçada por outra intérprete como forma de promover a inclusão do surdo na interação social, que vai além dos conteúdos pedagógicos previstos para cada aula.

"Eu tenho que interpretar, primeiramente, tudo que o professor fala. Agora, se um grupinho estiver lá atrás conversando ao mesmo tempo em que o professor tá falando, não. (...) Mas quando é aquele engraçadinho ou engraçadinha que vai lá na frente e começa a falar alto pra todo mundo ouvir, a turma inteira ouvindo, eu costumo interpretar sim, porque, se não, vai todo mundo rir e ele nem vai saber o porquê, então eu acho que acaba incluindo ele, nesse aspecto, quando há interação com a turma, quando o aluno interage com a turma, eu acabo interpretando, sim." (Carla, intérprete)

A intérprete Joana, por sua vez, relativiza a necessidade de traduzir para Libras todas as conversas paralelas que ocorrem em sala de aula, sugerindo que, excetuando o diálogo entre professor e aluno, o intérprete deva traduzir outras falas apenas por solicitação do aluno surdo.

"Tirando a parte que é nossa mesmo, parte aula, professor-aluno eu acho que tem que ser passado... Agora, quanto à questão do grupo, só o estritamente necessário, o desnecessário não. Até porque muita coisa não chama nem atenção do surdo, ele num tá nem aí, então, não tem nem por que você estar falando que o grupinho lá tá falando alguma coisa... Só se o surdo vier perguntar, "eles estão falando sobre o quê?". Aí sim..." (Joana, intérprete) 
Joana parece acreditar que informação demais pode ser prejudicial aos alunos surdos. Em alguns casos, Joana opta por assumir o papel do professor e busca simplificar a explicação dada inicialmente pelo professor. Note-se que, por não saber Libras, o professor não pode avaliar os possíveis efeitos dessa simplificação.

"Quem tem que dar a resposta é o professor. Então, se o aluno não consegue, não tá assimilando bem a questão, eu devolvo pro professor e falo que ele não entendeu nada ou busco outras formas de ensinar, porque, às vezes também, o professor, ele dá muita volta e isso acaba prejudicando o aluno surdo. Eu tento buscar uma forma mais resumida pra que a informação chegue. Se ele não entende, a dificuldade está na explicação do professor." (Joana, intérprete)

A possível falta de adequação das explicações do professor às necessidades dos surdos e, por outro lado, a simplificação proposta pela intérprete nos remetem ao fato apontado por Peluso e Larrinaga (1996) de que, muitas vezes, não são oferecidas aos alunos surdos as mesmas possibilidades de aprendizagem que as oferecidas aos ouvintes.

Com relação a como o intérprete deve agir diante de uma dúvida ou dificuldade de um aluno surdo, Carla relata que prefere solicitar que o professor faça uma nova explicação especificamente para o aluno, a fim de evitar possíveis erros conceituais caso ela própria explicasse ao aluno.

"Se o aluno tem uma dúvida, eu falo 'peraí, vou chamar o professor', chamo o professor, o professor vai até a mesa, faz uma nova, geralmente né, faz uma nova explicação e essa explicação eu interpreto especialmente para o aluno surdo que levantou a dúvida antes (...) Até porque a explicação da gente pode estar errada." (Carla, intérprete)

A fim de deixar bem marcado o papel do professor, Carla, conforme depoimento abaixo, também solicita que o próprio professor se dirija ao aluno surdo quando deseja chamar a atenção de um aluno. Ela quer mostrar para o aluno que é o professor quem está buscando manter a disciplina e não ela mesma, a intérprete. Isso pode contribuir para que os papéis de intérprete e professor fiquem mais claros, e as relações de status e poder em sala de aula, melhor definidas.

"É a mesma coisa quando vai brigar também... [imitando a fala do professor] 'ah, fala pra ele que ele num pode'. Eu digo, 'não, vai lá você, 
pode falar, que eu interpreto'. O professor que tem que falar 'senta, ó, para com isso', e eu vou fazendo em sinais.” (Carla, intérprete)

Com relação a situações em que os alunos têm dúvidas, a professora relata, em seu diário de pesquisa, ter observado, durante as aulas da turma observada neste trabalho, diferenças de atitudes entre alunos ouvintes e surdos.

"Outra coisa que me chamou atenção era que os alunos ouvintes perguntavam a mim o tempo todo, enquanto os surdos geralmente perguntavam ao colega surdo ou pediam ajuda ao intérprete quando tinham alguma dúvida." (Ana, professora, mediadora de tecnologia)

Isso mostra que o aluno surdo prefere se dirigir a alguém que saiba Libras (o intérprete ou um colega surdo) para tentar esclarecer sua dúvida, em vez de se dirigir ao professor (que não sabe Libras) e, então, solicitar a mediação do intérprete. Em outras palavras, o aluno surdo elege como seu interlocutor preferencial aquele que sabe sua língua materna e não aquele que, institucionalmente, tem o papel de ensinar. Se, por um lado, tal atitude pode valorizar a possibilidade de aprender com diferentes pessoas (e não apenas com o professor), por outro lado, como o professor não sabe Libras e não consegue acompanhar as conversas dos alunos surdos sobre suas dúvidas, a compreensão do docente sobre o processo de aprendizagem dos surdos é restringida. Manter o professor informado sobre as dúvidas dos alunos surdos dirigidas diretamente ao intérprete parece ser um procedimento recomendável.

Com relação à questão das escolhas do intérprete sobre o que deve interpretar, já discutida neste artigo, a professora indica, em seu diário de pesquisa, que nem sempre concordava com as escolhas feitas pelo intérprete. Embora não seja fluente em Libras, ela percebeu que nem sempre o intérprete interpretava para os alunos surdos tudo o que ela dizia.

"Houve momentos em que o intérprete não interpretou o que eu falava para todos os surdos, o que gerou conflitos, pois eu julgava ser importante para eles tudo o que eu dizia." (Ana, professora, mediadora de tecnologia)

O trecho de aula, transcrito a seguir, em que se discute a tradução de um termo em inglês usado no contexto da tecnologia, ilustra essa percepção da professora. 
PROFESSORA: E tag?

ALUNA SURDA: E-T-I-Q-U-E-T-A (digitaliza a palavra que achou como sendo a tradução para "tag").

PROFESSORA: É no sentido de rótulo. (O intérprete não interpreta, porque está conversando com outro grupo, mas a professora pede que a informação seja transmitida a todos.) Explica pra eles, Aldo. No Facebook, você marca a pessoa, bota o nome nas fotos. Ela bota meu nome nas fotos pra caramba, né? ( $O$ intérprete explica em Libras exemplificando que uma aluna acha a amiga e bota o nome, mas ele mesmo não entendia muito bem essa ação, pois não usava Facebook.) É isso, lembra que eu te falei que no Facebook marcam as pessoas? Isso que é a tag, Aldo.

Em outro trecho da mesma aula, transcrito a seguir, quando os alunos buscam o significado de "link", a professora pede ajuda ao intérprete para esclarecer para os alunos surdos os diferentes sentidos de "ligar" (fazer uma chamada telefônica e unir, juntar), porque ele não estava interpretando a fala da professora sobre o assunto.

PROFESSORA: E link, descobriu?

ALUNA SURDA: (oralizando) Ligação.

PROFESSORA: Ah, descobriu? Faz o sinal. (A aluna faz o sinal de ligação telefônica e soletra) Não, mas dá ideia de juntar, né, de ligar, não é ligar de telefone, não. (A professora tenta explicar em Libras, porque o intérprete julga não ser necessário interpretar a conversa para todos.) Melhor você explicar isso, Aldo. Olha lá pro intérprete Aldo, gente... Esse link aqui é de ligar, fazer uma ponte. (O intérprete chama a atenção de todos os surdos e faz o sinal de juntar, unir.)

\subsection{O professor e o uso de Libras}

Apesar da presença do intérprete de Libras em sala de aula, o fato de os professores saberem Libras parece ser um aspecto valorizado por todos os participantes. No depoimento a seguir, o aluno se ressente pelo fato de a maioria dos professores não saber Libras.

"Todo professor poderia saber pelo menos um pouco de Libras porque às vezes a gente senta na sala, fica olhando e não entende a oralização do professor, só fala, fala, fala... falta um pouco de Libras." (Joyce, aluna surda) 
A intérprete Carla também destaca a importância de o professor saber Libras para um relacionamento mais próximo entre professor e alunos.

"Eu acho que não é necessário ser fluente, porque nós estamos lá pra isso, mas eu acho prazeroso pro surdo o professor chegar e fazer o sinal de oi. (...) Acho importante que eles saibam alguns sinais pra pelo menos ter um contato, uma proximidade maior com o aluno." (Carla, intérprete)

A fim de facilitar a interação, nas aulas de inglês observadas neste estudo, a professora, apesar de não ser fluente em Libras, tenta, sempre que possível, utilizar a língua de sinais tanto para se comunicar com os alunos surdos quanto para ensinar alguns sinais para os alunos ouvintes. $\mathrm{O}$ trecho a seguir ilustra essa iniciativa da professora.

PROFESSORA: (faz os sinais em Libras, sem a ajuda do intérprete.) Ok, então, o nome, sua idade com o número em inglês e a cor que mais gosta. (A professora faz sinal de exemplo e completa as lacunas do texto no quadro com suas informaçôes) I am Ana Paula, I'm 33 years old (faz o sinal de idade e os alunos riem), é... estou velha (faz o sinal de velha) and my favorite color is (mostrando a blusa) white (fala, digitaliza e faz sinal da cor branca em Libras).

Em outro trecho de aula, transcrito a seguir, a professora pergunta ao intérprete qual é o sinal de "rede". O intérprete, então, mostra a existência de diferentes sinais para se referir a dois sentidos diferentes de uma mesma palavra - no caso, rede de balanço e rede de computadores - e aproveita para ensinar um pouco de Libras para a professora.

PROFESSORA: INTER+NET, duas palavras (mostrando as palavras). Hein, Aldo, qual o sinal de rede?

INTÉRPRETE: $O$ sinal literal de rede é assim (faz o sinal).

PROFESSORA: Mas deve ser rede de balanço...

INTÉRPRETE: É, agora, essa rede a gente faz assim, de conectado.

PROFESSORA: Hã, conectado, isso. (A professora repete o sinal.) Ó, olha pro Aldo (os surdos olhavam para a professora e não para o intérprete neste momento).

Com relação às dificuldades enfrentadas pelo professor para lecionar para uma turma com surdos e ouvintes, a intérprete Carla também acredita que, além do já citado desconhecimento de Libras por parte da maioria dos 
professores, o docente deveria estar mais preparado para planejar aulas com uma metodologia mais adequada aos alunos surdos, com ênfase nos recursos visuais, por exemplo.

"O professor, ele sabe como passar a matéria pro aluno ouvinte, mas pra passar pro aluno surdo ele não tem preparo, não tem o conhecimento. Não é culpa do professor, mas há a necessidade do professor tentar buscar isso, por exemplo, a questão da imagem, o surdo depende muito do visual. Como ele não tem a audição, então, ele usa o visual pra tudo. Então, seria uma aula mais dinâmica, uma aula mais visual, isso seria uma aula para surdo." (Carla, intérprete)

No depoimento a seguir, ao falar da capacitação que o docente deveria ter para atuar em turmas inclusivas, a professora de inglês aponta o conhecimento de Libras como o passo inicial para ajudar o professor a planejar atividades mais adequadas aos alunos surdos.

“(...) Inicialmente, que o professor dominasse Libras para que ele pudesse vislumbrar mais eficazmente o que se pode fazer/trabalhar com o aluno." (Eliane, professora de inglês)

A fala da professora sugere que a lacuna de formação docente é tanto de caráter linguístico (o fato de não saber Libras) quanto pedagógico (o fato de não saber a metodologia mais adequada aos alunos surdos) e reforça a posição de Medeiros e Ferreira (2009) de que, apesar das políticas públicas de inclusão, o professor ouvinte não recebe orientação ou formação adequada para ensinar alunos surdos.

\subsection{A mediação da tecnologia}

O uso da tecnologia em sala de aula é valorizado pelos alunos surdos, especialmente porque possibilita a utilização de vídeos, seja com legendas ou com janela de interpretação em Libras. No primeiro depoimento a seguir, o aluno destaca o uso de vídeos da Internet na sala de informática. No segundo depoimento, o aluno sugere o uso de vídeos em outras aulas, além da aula de inglês. Tal preferência por vídeos mostra a importância de elementos visuais para o processo de aprendizagem dos surdos, apontada por Berto (2012) e já comentada neste artigo.

"O inglês ele é muito diferente, o dicionário do meu computador me ajuda um pouco, mas lá na sala a professora mostra tudo em vídeo da internet." (Pedro, aluno surdo) 
“(...) Eles [outros professores] poderiam trabalhar mais com vídeo também, assim como a professora de inglês faz." (José, aluno surdo)

Os intérpretes também destacam a importância dos elementos visuais proporcionados pela Internet para a aprendizagem dos surdos, como se pode observar no trecho a seguir.

"Eu, assim, eu acho a informática tudo pro surdo, porque é o visual né, eles podem pesquisar... Aqui tem acesso à Internet, então, assim, a Internet é um mundo de informaçôes e isso é importante pro surdo também." (Carla, intérprete)

No caso das aulas de inglês, o suporte do visual - tanto pelo uso de imagens e vídeos da Internet, quanto de objetos concretos da sala de aulatambém permitiu que a professora utilizasse mais a língua inglesa, sem tanta necessidade de recorrer ao português. Isso foi positivo para ampliar o contato de todos os alunos (surdos e ouvintes) com a língua-alvo.

Particularmente nas aulas sobre termos em inglês relacionados à tecnologia, foi fundamental a possibilidade de demonstrar, na prática, o significado de algumas palavras com as quais alguns alunos surdos não estavam familiarizados. Como se pode observar no trecho de aula transcrito a seguir, esse foi o caso de "link", que só foi compreendido por uma aluna, quando a professora mostrou do que se tratava na tela do computador.

PROFESSORA: Hiperlink, o que que era link, lembra? ALUNA OUVINTE: Página.

PROFESSORA: Não, (soletrando) LINK. Que até eles fizeram, lembra, Aldo? (se dirige ao intérprete) os surdos fizeram assim quando leram (faz o gesto de telefone), mas não era esse ligar de telefone.

ALUNA SURDA: (oraliza e faz o sinal de telefone) Ligaçāo.

PROFESSORA: É, era ligação, mas não era ligação de telefone. (...)

ALUNA SURDA: (digitaliza para a câmera, mas intérprete e professora não veem) I-N-T-E-R-N-E-T.

PROFESSORA: É ligar de unir, de ter uma ponte pra ir a outro lugar, entre um lugar e outro.

ALUNA SURDA: (oraliza) É no bate papo, assim.

PROFESSORA: (interagindo com a aluna oralmente e sem a ajuda do intérprete, pois a aluna tem residuo, faz leitura labial e usa aparelho) Bate papo? 
Não, o link, ele fica assim, azul sublinhado, (mostra na tela) quando você tá lendo uma coisa... Quando você clica ali no azul, vai pra outra página (clica no link).

ALUNA SURDA: (faz leitura labial e oraliza) Ah, entendi.

Além dos recursos visuais proporcionados pela Internet, o fato de grande parte da comunicação mediada por computador ser feita por escrito (e não oralmente) também torna essa tecnologia adequada aos alunos surdos. No depoimento a seguir, a intérprete Carla destaca a possibilidade de os alunos surdos se comunicarem por escrito, em português, através da Internet.

"Eles (os alunos surdos) vivem num mundo de ouvintes e utilizam a língua portuguesa e não podem falar. Então, assim, ao menos, eles têm que saber a língua portuguesa escrita. Senão, eles vão tropeçar muito e nada melhor do que a internet." (Carla, intérprete)

Já Aldo, intérprete da turma em foco neste estudo, sugere a criação de uma rede social interna para atividades pedagógicas de comunicação escrita entre os alunos surdos, tanto em português quanto em inglês.

“(...) criar uma rede social interna, se pudesse fazer aqui, para eles se comunicarem havendo tipo uma conversa curta sobre um assunto de conteúdo escolar e que eles pudessem se comunicar escrevendo, isso seria ótimo pro surdo, né, entre eles... pra treinar o português também... poderia até fazer isso em inglês... tipo dar uma tarefa específica assim: "convida ele para almoçar em inglês", né?" (Aldo, intérprete)

$\mathrm{Na}$ visão da professora de inglês, as atividades desenvolvidas na sala de informática, com a mediação da tecnologia, estimularam a participação, o engajamento e a autonomia dos alunos, além de contribuir para que os alunos surdos se sentissem mais capazes.

"Os alunos participaram bastante através dos projetos propostos para reforçar e atualizar o aprendizado (...) eles vão em busca das informações e se desenvolvem (...) acredito que inserir tecnologias digitais nas aulas seja uma boa proposta já que possibilitará aos nossos alunos maior independência na busca de conhecimento... é mais um instrumento para que perceba que sua deficiência não é uma barreira para que ele tenha acesso à qualquer informação (...)" (Eliane, professora de inglês) 
Embora valorize as atividades mediadas pelas tecnologias digitais, a professora de inglês não se sente confortável em utilizá-las em sala de aula, confirmando o que Bonilla (2011) sugere sobre a relação de alguns professores com as novas tecnologias. Dessa forma, no contexto investigado, o uso de tecnologias digitais se restringiu às aulas de inglês ministradas na sala de informática, nas quais a mediadora de informática assumiu o papel de professora da disciplina.

Conforme seu depoimento abaixo, a exemplo da professora de inglês, o intérprete Aldo também acredita que as atividades na sala de informática facilitam a interação entre todos os alunos e a aprendizagem dos alunos surdos.

"O aprendizado do surdo na sala de informática com ouvintes é muito maior do que a aprendizagem de um surdo sozinho na aula." (Aldo, intérprete)

Já a mediadora de tecnologia acredita que nem sempre houve interação para aprendizagem durante as aulas de inglês na sala de informática, tendo observado conflitos. $\mathrm{Na}$ aula em foco a seguir, os alunos estão trabalhando no computador em dupla, sendo um aluno ouvinte e outro surdo. No trecho transcrito abaixo, um dos ouvintes deixa transparecer que acredita que trabalhar em dupla com um surdo é somente deixar o colega copiar o que ele pesquisou sozinho. Ele parece acreditar ser superior ao colega surdo, que, para ele, não conseguiria sozinho achar a resposta. A professora, então, interveio ressaltando a natureza colaborativa da atividade e a capacidade do aluno surdo para o aluno ouvinte.

ALUNO OUVINTE: Professora, tá colando do meu aqui. ALUNO SURDO: Ele cola do meu. Não posso colar dele?

PROFESSORA: Não é colar, pode fazer junto. Até porque não tem computador pra todo mundo. O problema é que vocês não estão trabalhando juntos.

ALUNO SURDO: Tamo sim.

PROFESSORA: Não, estão brigando, estão entrando em conflito. Ai num dá, né? Se você quisesse fazer em união, podia fazer junto.

ALUNO OUVINTE: Vai, copia logo, então. Copiou?

PROFESSORA: Por que que ele não pode olhar do seu?

ALUNO OUVINTE: COPIA, cara!

PROFESSORA: Por que que o colega, por que que um não pode ajudar o outro? 
Eu, hein? Egoísmo!

ALUNO SURDO: Oh, professora?

ALUNO OUVINTE: Não consegue nem achar...

Conflitos como o observado no trecho acima podem ocorrer a partir da interação entre alunos surdos e ouvintes, mas, como apontado por Lodi (2005), são fundamentais para o desenvolvimento dos alunos surdos. Conforme já mencionado, para a autora, os alunos surdos precisam intensificar as relações dialógicas com seus pares e com os ouvintes e a surdez deve ser entendida como parte da pluralidade humana.

Além de conflitos durante a realização de atividades em dupla, a professora também percebeu a dificuldade do uso de Libras devido à configuração espacial da sala (com computadores encostados junto às paredes) e da posição dos alunos durante as atividades com uso do computador, conforme se pode observar no registro em seu diário de pesquisa abaixo.

"Sobre minha prática, (...) pretendo me esforçar para não mais falar em voz alta enquanto circulo entre os alunos durante a execução da atividade, pois percebi, através da filmagem da aula, que, como os alunos surdos estavam concentrados diante do computador e consequentemente de costas para mim e para o intérprete, não podiam fazer leitura labial ou ver o intérprete interpretando o que eu dizia." (Ana, professora, mediadora de tecnologia)

Outro problema observado nas aulas de inglês com mediação da tecnologia foram limitações de infraestrutura e de recursos técnicos e humanos. Dentre elas, podemos apontar o pequeno número de computadores, conexão instável à Internet, espaço reduzido da sala de informática e o número elevado de alunos por turma. No registro do diário de pesquisa abaixo, a professora descreve como a falta de Internet limitou as atividades previstas para aquela aula.

"Os alunos completaram seus textos (...) salvamos os arquivos para mandar posteriormente para o e-mail da professora (porque a sala estava sem internet, aliás o previsto era usar o Google Docs nesta atividade)... como alguns queriam colocar imagens da internet/facebook, a maioria deixou para ilustrar na aula seguinte...”(Ana, professora, mediadora de tecnologia) 
Além disso, nem todas as turmas podem ser atendidas na sala de informática. Talvez a solução para isso seja investir em mais recursos e capacitar os professores regentes a levar as NTICs para a sala de aula e não apenas levar os alunos para a sala de informática.

\section{CONSIDERAÇÕES FINAIS}

Se, por um lado, o contexto de ensino de inglês para uma turma inclusiva, onde ocorre a mediação de três diferentes línguas (inglês, português e Libras), é percebido pelos alunos (surdos e ouvintes) como uma oportunidade de aprendizagem dessas línguas, por outro lado, as dificuldades dos alunos surdos com a aprendizagem de sua própria língua materna (Libras) e do português como segunda língua tornam a aprendizagem de uma terceira língua (o inglês) ainda mais desafiadora. Entretanto, as especificidades do processo de aquisição de línguas pelos surdos não impedem que aprendam a modalidade escrita de uma língua estrangeira, como o inglês.

Com relação às atividades orais em aulas de inglês para turmas com alunos surdos e ouvintes, é preciso que haja uma adaptação do plano de aula para que os surdos não se sintam excluídos, sem retirar dos alunos ouvintes o direito ao desenvolvimento das habilidades orais.

Em aulas de inglês, por vezes, o professor acaba usando o português para viabilizar o trabalho do intérprete que desconhece essa língua estrangeira. Se, entretanto, o objetivo é oferecer aulas de inglês para turmas inclusivas, seria ideal que o intérprete dessas aulas também tivesse conhecimento de língua inglesa.

Sobre o papel do intérprete de Libras, percebe-se a importância de este não se limitar a interpretar apenas as interaçôes entre professor e alunos com foco instrucional, mas incluir também a interação entre alunos e enunciados que promovem a socialização do grupo. As escolhas do intérprete sobre o que precisa ou não ser interpretado, entretanto, nem sempre coincidem com a opinião do professor. Dessa forma, é recomendável que intérprete e professor conversem sobre os critérios a serem adotados. Isso também se aplica à questão do esclarecimento de dúvidas dos alunos surdos pelo intérprete. Além de evitar o risco de o intérprete não consultar o professor e incorrer em possíveis equívocos, é importante que o professor seja informado pelo intérprete sobre as dúvidas dos alunos para melhor compreender seu processo de aprendizagem.

$\mathrm{O}$ fato de os participantes valorizarem o conhecimento (ainda que reduzido) de Libras pelo professor de inglês sugere que este deva buscar 
aprender pelo menos alguns sinais como forma de se aproximar dos alunos surdos. Além disso, a capacitação pedagógica do professor para utilizar recursos e métodos mais adequados a turmas inclusivas se mostra claramente necessária.

Com referência à mediação das novas tecnologias no ensino de inglês para turmas inclusivas, destacam-se como pontos positivos a facilidade de acesso a imagens e vídeos (especialmente importantes para alunos surdos) e o sentimento de realização dos alunos ao se engajarem em atividades de navegação e busca na Internet. A falta de infraestrutura (como poucos computadores, conexão à Internet instável etc.), entretanto, limita a utilização das NTICs. Cumpre buscar ainda uma disposição dos equipamentos em sala que facilite a interpretação de/para Libras.

Apesar das limitações do seu escopo, espera-se que este estudo, além de apontar alguns desafios e possibilidades do ensino de inglês mediado pelo uso das NTICs e da Libras para surdos e ouvintes, possa incentivar o desenvolvimento de mais pesquisas sobre esse tema na área de Linguística Aplicada.

\section{REFERÊNCIAS}

BERTO, D. M. P. Ensino de Língua Inglesa para Alunos Surdos, Planeta Educação, 2012. Disponível em: <http://www.planetaeducacao.com.br/portal/artigo. asp?artigo $=2307>$. Acesso em: 8 fev. 2013.

BONILLA, M. H. Formação de professores em tempos da web 2.0. In: FREITAS, M. T. (Ed.) Escola, tecnologias digitais e cinema. Juiz de Fora: Editora da UFJF, 2011. BRASIL, Ministério da Educação. Parâmetros Curriculares Nacionais. Terceiro e quarto ciclos do ensino fundamental. Secretaria de Educação, Brasília: MEC, 1998. Disponível em: $<$ http://portal.mec.gov.br/seb/arquivos/pdf/pcn_estrangeira.pdf $>$. Acesso em: 22 jun. 2013.

CARVALHO, R. A. M. Desafios do ensino da língua inglesa para surdos. In: Anais do VIII Seminário de Línguas Estrangeiras: a formação e a prática de professores de línguas estrangeiras, 2013. Goiânia: FUNAPE, Faculdade de Letras da UFG, 2013. Disponível em: <http://www.letras.ufg.br/uploads/25/original_VIISLE_08.pdf>. Acesso em: 13 mai. 2013.

FONSECA-JANES, C. R. X. Modelo para mudanças de atitudes sociais em relação à inclusão. Revista Galego-portuguesa de Psicoloxía e Educación, vol.20, n.1, ano17, 2012, p.83-98 Disponível em: <http://www.educacion.udc.es/grupos/gipdae/ documentos/revistas/20.pdf>. Acesso em: 12 fev. 2014. 
GARCIA, B. G. Acquisition of English Literacy by Signing DeafChildren. Revista Ponto de Vista, Florianópolis, n.5, p.129-150, 2003. Disponível em: <http://www. perspectiva.ufsc.br/pontodevista_05/07_garcia.pdf>. Acesso em: 13 mai. 2013.

GESSER, A. Libras? Que língua é essa?: crenças e preconceitos em torno da língua de sinais e da realidade surda. São Paulo: Parábola Editorial, 2009. 88p.

LODI, A. C. B. Plurilinguismo e surdez: uma leitura bakhtiniana da história da educação dos surdos. Educação e Pesquisa, vol.31, no.3, p.409-424, 2005. Disponível em: <http://www.redalyc.org/articulo.oa?id=29831306>. Acesso em: 13 mar. 2013.

MARCUSCHI, L. A. Da fala para a escrita: atividades de retextualização. São Paulo: Cortez, 2010. 136p.

MEDEIROS, T. G.; FERREIRA, M. C. F. D. Inglês para alunos surdos: quem será de fato o incluído - o professor ou o aluno? Revista Virtual de Cultura Surda e Diversidade, Petrópolis, n.5, 2009. Disponível em: <http://editora-arara-azul.com. br/novoeaa/revista/?p=209> Acesso em: 22 jan. 2014.

MICCOLI, L. Autonomia na aprendizagem de língua estrangeira. In: PAIVA, V. L. M. O. (Ed.). Práticas de ensino e aprendizagem de inglês com foco na autonomia. Belo Horizonte: Faculdade de Letras da UFMG, 2005.

PELUSO, L.; LARRINAGA, J. A. Los sordos y la lengua oral: una aproximación al espaňol de la comunidad sorda de Montevideo. Montevideo: Universidad de La Republica, 1996, 99p.

SELINKER, L. Interlanguage. In: International Review of Applied Linguistics, v. 10, p. 209-232. 1972.

SILVA, C. M. O. O surdo na escola inclusiva aprendendo uma língua estrangeira (inglês): um desafio para professores e alunos. 2005. 230f. Dissertação (Mestrado em Linguística Aplicada) - Instituto de Letras, Universidade de Brasília, 2005. Disponível em: <http://pgla.unb.br/ingles/images/Dissertacoes/2005/Claudney_ Maria_de_Oliveira_e_Silva.pdf >. Acesso em: 01 jan.2014.

Data de submissão: 14/04/2014. Data de aprovação: 01/09/2014. 